\title{
Attitudes, practices and beliefs towards worksite smoking among administrators of private and public enterprises in Armenia
}

\author{
Narine K Movsisyan, ${ }^{1}$ Michael E Thompson, ${ }^{2}$ Varduhi Petrosyan ${ }^{1}$
}

${ }^{1}$ Center for Health Services Research and Development, American University of Armenia, Yerevan, Armenia ${ }^{2}$ Department of Public Health Sciences, University of North Carolina at Charlotte, Charlotte, North Carolina, USA

\section{Correspondence to} Dr Narine Movsisyan, Center for Health Services Research and Development, American University of Armenia, 40 Marshal Baghramian, 208W Yerevan 0019 Armenia; nmovsesi@aua.am

Received 15 June 2009 Accepted 18 November 2009 Published Online First 15 June 2010

\section{(2) UNLCKI:}

This paper is freely available online under the BMJ Journals unlocked scheme, see http:// tobaccocontrol.bmi.com/site/ about/unlocked.xhtml

\begin{abstract}
Background In March 2005, Armenia enacted legislation protecting employees from secondhand smoke. This research was the first attempt to understand the attitudes, beliefs and practices of managers of public and private enterprises regarding smoke-free worksite policies.
\end{abstract}

Methods Mixed methods were used. The study team conducted focus group discussions with worksite administrators to explore their beliefs, attitudes and practices related to worksite smoking. These findings guided development of a quantitative instrument to collect more representative data on the same issues. Using stratified random sampling, 243 worksites were interviewed from June-July 2005, representing state/ municipal, health, educational, culture and business institutions in three of Armenia's largest cities.

Results/Discussion Smoking-related practices differed significantly across institutions. More than half of the managers $(55.6 \%)$ reported having smoking restrictions at worksites, including $37.0 \%$ who reported smoke-free workplaces; however, smoking or the presence of ashtrays was observed in $27.8 \%$ of workplaces reported to be smoke-free. A substantial proportion of the administrators favored both banning indoor smoking and allowing smoking in special areas. Only $38.0 \%$ of managers were aware of employees' existing legal protections from exposure to secondhand smoke. Knowledge of these regulations was not related to adherence to smoke-free worksite policies. The research also revealed widespread confusion between the concepts of worksite smoking restrictions and smokefree workplaces. Public awareness campaigns that promote promulgation and enforcement of worksite smoking regulations could increase employee demand for smoke-free worksites.

Conclusion As one of the first studies to investigate smoking-related worksite practices, attitudes and beliefs in former Soviet countries, these findings provide insight into law enforcement processes in economies in transition.

\section{BACKGROUND}

Workplace smoking is a significant problem in many countries, particularly those with low and middle incomes and economies in transition. Exposure to secondhand smoke (SHS) has both immediate and long-term health effects. It increases the risk of asthma, heart disease, obstructive chronic respiratory illnesses and lung cancer. ${ }^{12}$ The economic and health costs of smoking and passive smoking include, but are not limited to, (i) higher absenteeism from work through illness and lower productivity, and (ii) excess disability caused by chronic obstructive pulmonary and cardiovascular disease. ${ }^{12}$ The level of protection against worksite exposure to tobacco smoke varies widely across regions and countries. In the USA, the median percentage of employees working in smoke-free indoor workplaces was $73.4 \%$ (2006), while that number was $51.0 \%$ in the UK (2005). ${ }^{2}{ }^{3}$ Little data exist about SHS worksite exposure in former Soviet countries.

Armenia, a former Soviet Republic, is a country in transition with a population of 3.2 million. ${ }^{4}$ Although the political situation has stabilised and economic indicators have improved over the last several years, positive changes in health indicators have been minimal. ${ }^{4}$ Moreover, chronic diseases remain the leading causes of morbidity and premature death as a result of unhealthy lifestyle coupled with insufficient access to quality healthcare services. ${ }^{5} 6$

In late 2004, the country committed itself to improving the public's health through accession to the WHO's Framework Convention on Tobacco Control (FCTC) and adopted new policy measures to restrict smoking in workplaces. ${ }^{7}$ On 24 December 2004, the National Assembly of Armenia adopted a law that banned smoking in educational, healthcare and cultural institutions and restricted smoking in all other worksites except bars, cafes and restaurants (Article 11 of the Republic of Armenia Law 'On Restrictions of Tobacco Sale, Consumption and (Use'); the law came into force in March 2005. This study was conducted in June 2005 , shortly after the law was enacted. No data assessing smoke-free workplaces in Armenia prior to this study are available. This article reports public and private business administrators' beliefs and attitudes on worksite smoking-related policies as well as current worksite practices.

\section{METHODS}

\section{Study design}

A combination of qualitative and quantitative approaches was used. The qualitative component included focus group discussions (FGD) with administrators of public and private institutions. The FGDs explored attitudes, beliefs and smokingrelated worksite practices. This information guided development of a subsequent quantitative survey. The cross-sectional survey measured the attitudes, beliefs and practices of administrators and managers of public and private institutions in three of Armenia's largest cities-Yerevan, Gyumri and Vanadzor. These cities were selected because the 
majority of medium and large businesses are located in these urban areas, enabling convenient access to a concentration of eligible businesses. Inclusion criteria for both the qualitative and quantitative components were: public institutions in health, education, culture or governance areas; and registered private business enterprises with at least 15 full time employees. Small businesses (private businesses with less than 15 employees) were excluded since they were often not formally registered and therefore, (i) their contact information was not available in the directories and (ii) no other reliable inventory of small business enterprises existed.

\section{Sampling}

Worksites were selected from the Yellow Pages Armenia 2005. The Yellow Pages contains an accurate listing of all officially registered businesses. Three FGDs were conducted with a crosssection of mid-level administrators representing state, health, educational and business institutions (each with 4-5 participants for a total of 13 participants) before reaching data saturation. Each focus group discussion lasted approximately 90 minutes. The sessions were audiotaped with participants' permission to facilitate the subsequent analysis.

The sample size to achieve estimates with $10 \%$ precision for the quantitative survey was estimated at 245 . To maintain proportionality to the population size of these three cities 196 interviews were targeted for Yerevan, 29 for Gyumri and 20 for Vanadzor. To increase the heterogeneity of the sample and the generalisability of the results, the listing of businesses within each city was stratified by type (state/municipal organisations; healthcare facilities; educational institutions; cultural organisations; business enterprises) and proportionately sampled (stratified random sampling). A sample of 346 potential respondents was drawn to allow for losses for non-responses, refusals and other loses to achieve the target of 245 completed interviews. An interviewer then made a preliminary phone call to the selected businesses to screen for eligibility (having 15 or more employees), to verify the contact information for the top-level manager/administrator and to make an appointment for the visit.

\section{Instruments}

After reviewing the literature, the study team developed a guide for focus group discussions that covered the following areas: awareness of adverse effects of passive smoking and the existing non-smoking policies, attitudes toward smoking in the workplace and adherence to existing non-smoking policies, beliefs about enforcement of non-smoking laws and awareness of the FCTC.

Based on the FGD results, the study team developed a questionnaire. The questionnaire consisted of 60 questions covering the following domains: general information about the institution; attitude toward worksite smoking in general; attitude and practices at the particular worksite; and personal attitude towards smoking. The questionnaire also included a structured observation guide for interviewer-observed practices at the time of the visit. Interviewers were instructed to visit as much of the facility as possible, but did not have to observe the entire facility to validate reported practices. The questionnaire was tested in the field and final adjustments were made; the interviewers were trained before the fieldwork.

\section{Ethical considerations}

The institutional review board (IRB) of the American University of Armenia approved the research protocols and instruments. Oral consent was obtained from all participants.

\section{Data collection and analyses}

The team of interviewers administered the survey in June-July 2005. The research team completed data entry, cleaning and descriptive analysis using SPSS 10 . The research team obtained summary statistics, such as frequencies and means and performed cross-tabulations and $\chi^{2}$ test to reveal significant relations between variables.

\section{RESULTS}

\section{Focus group discussions}

While the FGDs revealed a variety of opinions, the participants were generally aware of the hazards of SHS and would support restrictive measures. However, many lacked understanding of the implications of anti-smoking policies at their workplaces. The majority were aware of neither the FCTC nor the national tobacco control law. These findings guided development of the quantitative survey questionnaire.

\section{Survey}

The team of interviewers attempted to contact 346 institutions. Seventy-one per cent (246) of these attempts resulted in a completed interview. Three interviews were excluded from the sample because of inadvertent double interviewing of the same institutions, leaving a final sample of 243. The response rate varied across the strata with the highest response from state institutions $(100.0 \%)$ and the lowest from business enterprises (58.1\%).

\section{Survey participants}

Survey respondents were managers and administrators in 243 public and private institutions in three cities of Armenia. The majority of public institutions had 50-100 or more employees. The majority of private enterprises had 15-50 employees, with $33.0 \%$ having more than 100 employees. Information on study participants is summarised in table 1.

Respondent demographic data were collected, including age, gender, level of education and smoking status. The majority of the respondents $(96.0 \%)$ had university level education. The male:female ratio was near 2:1 (158:63). Mean age of the respondents was 47.6 years, ranging $21.0-78.0$ years. Daily smokers comprised $35.3 \%$ of the sample, with a fivefold higher prevalence in men (48.7\% in men vs $9.6 \%$ in women). Compared to smoking rates in the general population, a lower proportion of male managers reported smoking (males: $48.7 \%$ vs $60.5 \%$ of the general population) and a higher proportion of female managers reported smoking (females: $9.6 \%$ vs $2.0 \%)^{8}$

\section{Attitudes and beliefs towards smoke-free workplaces}

The vast majority (95.5\%) of respondents supported smoking bans in health, educational and cultural institutions. Eighty-one per cent supported smoking restrictions in all (public and private) worksites. Nearly $70.0 \%$ of the respondents supported a total ban of indoor smoking (table 2). Attitudes towards smoke-free workplaces did not significantly differ among managers by type of organisation, geographical location, gender, or occupation. Attitudes towards workplace smoking bans did differ significantly by respondent smoking status, with non-smokers more likely to support bans $(89.2 \%$ vs $65.9 \%, p<0.001)$.

Of the 243 respondents, $86.8 \%$ believed that tobacco smoke contains carcinogens. More than half of respondents (63.2\%) thought that banning smoking might have a positive effect on productivity. When asked about the possible effects on the economic impact of non-smoking policies, $58.3 \%$ of the 
Table 1 Respondents by type of institutions and number of employees $(n=243)$

\begin{tabular}{|c|c|c|c|c|c|}
\hline \multirow[b]{3}{*}{ Type of institution } & \multicolumn{5}{|c|}{ Number of full-time employees \% (n) } \\
\hline & \multicolumn{2}{|c|}{ Small } & \multicolumn{2}{|l|}{ Medium } & \multirow{2}{*}{$\begin{array}{l}\text { Large } \\
100+\end{array}$} \\
\hline & $<15$ & $15-25$ & $26-50$ & $51-100$ & \\
\hline State/municipal $(n=117)$ & $2.6(3)$ & $11.1(13)$ & $15.4(18)$ & $25.6(30)$ & $45.3(53)$ \\
\hline Mixed $(n=5)$ & - & $20.0(1)$ & - & $20.0(1)$ & $60.0(3)$ \\
\hline Other* $(n=4)$ & $25.0(1)$ & $25.0(1)$ & $25.0(1)$ & - & $25.0(1)$ \\
\hline
\end{tabular}

*These institutions were not identified as state, private or mixed property.

managers of private business enterprises believed that restricting smoking in the workplace might have a positive effect on profits. Sixty-seven per cent of the respondents agreed that strong leadership was essential to banning workplace smoking. Support for fines and other punitive measures was equivocal, with non-smokers being more supportive than smokers $(\mathrm{p}<0.001)$.

\section{Awareness of tobacco control regulations; worksite smoking practices}

Only $38.0 \%$ of the participants were aware of the new Armenian law restricting workplace smoking. More than half of the managers $(55.6 \%)$ reported having some worksite smoking restrictions. Among those reporting worksite restrictions, the majority $(76.0 \%)$ believed that they were set at the institutional level, with only $13.6 \%$ aware of the state law.

Smoking restrictions were more common at medical and cultural institutions $(76.0 \%$ and $72.0 \%$, respectively). Managers of $37 \%$ of all places surveyed reported that their workplace was smoke-free. In $27.8 \%$ of these workplaces, however, the interviewer observed smoking and/or the presence of ashtrays.

Smoking-related reported practices differed significantly across institutions. The majority of state and private business enterprises did not have smoking restrictions, while the majority of medical, educational, cultural institutions reported being smoke-free. A low proportion of smokers was associated with a higher likelihood of a workplace being smoke-free. Only $20.0 \%$ of managers at non-smoke-free workplaces believed that their workplace would become smoke-free in 6 months.
Twenty-three per cent of the managers indicated that smoking was permitted in all indoor areas, 35.8\% in hallways, $19.3 \%$ in a break room/cafeteria and $13.6 \%$ in a separately ventilated smoking room. Managers of health facilities more often reported being compliant with smoke-free policies in their rooms compared to managers of educational, business, culture and government facilities $(33.0 \%$ vs $22.0 \%, 12.0 \%, 11.0 \%$ and $3.0 \%$, respectively). Conspicuous 'No Smoking' signs were observed in 89 worksites (36.6\%), most often in hallways. Educational (50.0\%) and medical facilities (60.0\%) were more likely to post such signs.

Perceived reinforcing factors for implementing smoke-free worksite policies

About $40.7 \%$ of the managers thought that employee demand would spur implementation of a non-smoking policy at their worksite. For $35.0 \%$ of private and state employers, the health of employees and a state law would be equally important reinforcing factors. Liability of employers and worksite safety were mentioned as reinforcing factors by $31.3 \%$ and $23.5 \%$ of managers, respectively. Public (customer) image was of concern among $17.8 \%$ of the respondents. Private managers were less likely than government administrators to favour state laws regulating smoking $(22.2 \%$ vs $47.0 \%, \mathrm{p}=0.001)$.

Barriers to implementing smoke-free worksite policies

More than half (51.9\%) of the managers reported the 'mentality/ culture of tolerance' as an obstacle to implementing smoke-free worksite policies. Lack of enforcement mechanisms (such as

Table 2 Attitudes towards smoke-free policy among survey participants (\% (n))

\begin{tabular}{|c|c|c|c|c|c|}
\hline Statement & SA & A & $\mathbf{N}$ & D & SD \\
\hline $\begin{array}{l}\text { Indoor smoking should be banned in all } \\
\text { health, educational and cultural } \\
\text { institutions }\end{array}$ & $78.6(191)$ & $16.9(41)$ & $1.2(3)$ & $2.9(7)$ & $0.4(1)$ \\
\hline Smoking should be allowed only outdoors & $36.6(89)$ & $32.9(80)$ & $9.9(24)$ & $18.9(46)$ & $1.6(4)$ \\
\hline $\begin{array}{l}\text { Smoking areas should be designated at all } \\
\text { worksites }\end{array}$ & $52.3(127)$ & $35.4(86)$ & $3.3(8)$ & $6.2(15)$ & $2.9(7)$ \\
\hline \multicolumn{6}{|c|}{ Supports indoor smoking bans in all (state and private) institutions* } \\
\hline Non-smokers $(n=157)$ & $65.6(103)$ & $23.6(37)$ & $4.5(7)$ & $4.5(7)$ & $1.9(3)$ \\
\hline Daily smokers $(n=85)$ & $51.8(44)$ & $14.1(12)$ & $15.3(13)$ & $17.6(22)$ & $1.7(4)$ \\
\hline \multicolumn{6}{|c|}{ Supports fines and other punitive measures to enforce smoking bans* } \\
\hline
\end{tabular}

*Difference between smokers and non-smokers is significant, $\mathrm{p}<0.001$.

$\mathrm{SA}$, strongly agree; $\mathrm{A}$, agree; $\mathrm{N}$, neither agree nor disagree; $\mathrm{D}$, disagree; $\mathrm{SD}$, strongly disagree. 
fines) and lack of follow-up measures also were frequently mentioned as obstacles to implementing smoke-free workplace policies $(21.4 \%$ and $26.3 \%$ of respondents, respectively).

Potential obstacles such as lack of space, lack of incentives and implementation costs were not perceived as important barriers. Lack of information on existing regulations was mentioned by $16.7 \%$. One of five respondents (19.8\%) believed that no barriers existed to implement smoke-free policies. This belief was two times higher among managers of workplaces reported as smokefree $(p=0.001)$.

\section{DISCUSSION}

The sampling methodology had several limitations. Stratified random sampling from purposefully selected cities was limited to five categories of workplaces. Other categories such as hotels, cafes, restaurants and public transportation were excluded from the study. In addition, the sample size and methodology did not allow for statistical comparisons across geographical locations and category of workplace. Furthermore, rural worksites and small private businesses were excluded from the survey. Therefore, the results of the survey could be generalised to urban worksites of mainly medium and large sizes only. The lower response rate among private business worksites (58.1\%) may mask lower compliance with tobacco control regulations at private worksites.

This study found $81.0 \%$ support for banning smoking across the whole survey sample and $95.5 \%$ support from the managers and administrators in health, educational and cultural institutions. Nearly $70.0 \%$ of respondents thought that smoking should be allowed only outdoors.

Similar to findings from other studies, support for smoking restrictions at workplace was closely related to the smoking status of respondents. ${ }^{9} 10$ Smokers were less supportive of smoke-free worksite policies than non-smokers. This pattern did not differ by gender.

Despite the high level of support for smoke-free policies expressed by managers, only one-third of the workplaces reported being smoke-free; however, clear signs of smoking were observed in nearly one-third of the reportedly smoke-free worksites. These findings are more than five times higher than in the study by Goodin and McAllister that assessed compliance with anti-smoking legislation among Australian businesses. ${ }^{11}$

This study revealed a common misunderstanding among public and private administrators of the concept of an 'indoor smoking ban'. A significant proportion of respondents simultaneously favoured banning indoor smoking and allowing smoking in special and/or ventilated areas. This may suggest lack of understanding and differentiation between 'bans' and 'restrictions' among the administrators.

This research documented that the presence of smoking policies and compliance with them varied across worksite type. Medical, educational and cultural institutions were more prone to have smoke-free policies and to adhere to them. This finding is consistent with findings from the Australian study, confirming that type of business influences compliance. ${ }^{11}$

The 'culture of tolerance' was the most frequently cited obstacle to implementing smoke-free policy; liability and work safety issues were not reported to be important factors. Respondents suggested that strong leadership is essential to ban smoking at workplace; they also emphasised that employee demand for smoke-free worksites would be the most important factor contributing to better compliance with the existing laws. Importantly, data from a population-based survey implemented in Armenia at the same time as this study demonstrated strong public support for a smoke-free environment. ${ }^{12}$ Further study of employee attitudes toward smoke-free worksite policies could help guide development of specific recommendations that improve compliance with workplace smoking bans and restrictions that build upon the momentum of wide public support for smoke-free environments.

The study demonstrated that awareness among managers of the national law regulating worksite smoking remained quite low 3 months after its enactment. Awareness of the law was higher among these managers than among the general public $(38.0 \%$ vs $13.8 \%){ }^{12}$ This awareness, however, is still far lower than desired levels. Disconcertingly, adherence to worksite smoke-free policies was not related to the managers' awareness of the law. Adherence to smoking restrictions in settings where managers were not aware of the new national law could reflect pre-existing (Soviet) policies that restricted smoking in medical and educational settings and fire safety regulations that restricted smoking in industrial settings. It is therefore doubtful that increasing awareness of the new national law restricting worksite smoking, without other coordinated reinforcing efforts, will have the desired effect of increasing compliance with the law.

\section{POLICY AND RESEARCH IMPLICATIONS}

The study team translated these research findings into policy recommendations for tobacco control policy implementers in Armenia. These results were presented and discussed in meetings with various stakeholders, including state and municipal officials, policymakers, public administrators and the public Coalition for Tobacco Free Armenia. In addition, the research team prepared a policy brief that included specific recommendations for the Ministry of Health, the government of Armenia and relevant parliamentary committees. ${ }^{13}$ The recommendations emphasised the following:

- Adopting new, more effective communication mechanisms for informing the public, both targeted entities and the general public, about new laws such as the one restricting worksite smoking;

- Communicating clear messages about the content of the law and emphasising employer liability, workplace safety and the health of their employees;

- Emphasising the importance of senior management compliance with worksite restrictions established by the national law; and

- Establishing an enforcement mechanism (including fines and inspection) that assures compliance with worksite smoking law. (Note: In response to the policy briefing arising from this study and the active lobbying effort of the Coalition for Tobacco Free Armenia, among other efforts by Armenian tobacco control advocates, the law was amended in June 2009 to provide these enforcement mechanisms.)

The research team also recommended conducting in-depth case studies of institutions with successful smoke-free policy to distil and disseminate lessons from their positive experience.

\section{CONCLUSIONS}

This article represents one of the first studies to investigate smoking-related worksite practices, attitudes and beliefs in a former Soviet country. These results can help researchers and policy-makers better understand how to reach the goal of ensuring smoke-free worksites in transitional economies. These findings suggest that law enforcement processes in Armenia and 


\section{What this paper adds}

- Workplace smoking is a significant problem in many countries, particularly those with low and middle incomes and economies in transition, but little knowledge exists specific to former Soviet countries.

- This study explored smoking-related policies and the attitudes and beliefs of worksite managers and administrators toward those policies, at public and private worksites in three major Armenian cities.

- Smoking-related practices differed significantly across institutions. The research revealed widespread confusion between the concepts of worksite smoking restrictions and smoke-free workplaces.

- The results suggest that law enforcement processes in formerly Soviet countries may differ from those in industrialised countries, where smoke-free regulations are (generally) successfully self-enforced.

- These findings suggest strategies for strengthening smokefree worksite policies and increasing adherence for policymakers and the tobacco control community.

other post-Soviet countries may differ from those in industrialised countries, where smoke-free regulations are (generally) successfully self-enforced. Future interventions in Armenia and similar settings should include targeted public awareness campaigns about newly adopted legislation for employers (emphasising their responsibilities) and employees (emphasising their rights) coupled with effective monitoring and enforcement mechanisms.

Smoke-free policies not only protect non-smokers from worksite exposure to secondhand smoke and its associated health risks, but also encourage smokers to reduce consumption or even quit leading to a decrease in smoking in the home. ${ }^{14}$ These benefits are stronger in settings with complete bans and adherence to the policies. ${ }^{15}$ Although the Armenian legislation provides only partial protection for employees and does not cover all workplaces, appropriate, visible enforcement of the existing law could significantly reduce employees' exposure to secondhand smoke while efforts to strengthen and expand the legislation continue.

Acknowledgements The study team thanks Dr Hana Ross for her input in the planning of this research project.
Funding This study was carried out within a grant from Research for International Tobacco Control (RITC) and the International Development Research Center (IDRC) in Ottawa, Canada supported by the Canadian Tobacco Control Research Initiative (CTCRI) and the American Cancer Society (ACS).

\section{Competing interests None.}

Ethics approval This study was conducted with the approval of the Institutional Review Board (IRB) of the American University of Armenia, Yerevan, Armenia.

Provenance and peer review Not commissioned; externally peer reviewed.

\section{REFERENCES}

1. World Health Organization. International agency for research on Cancer. IARC monographs on the evaluation of carcinogenic risks to humans Vol. 83. Tobacco Smoke and Involuntary Smoking, 2002. http://monographs.iarc.fr/ENG/Monographs/ vol83/volume83.pdf.

2. Anon. State-specific prevalence of current cigarette smoking among adults and secondhand smoke rules and policies in homes and workplaces - United States, 2005. Center for Disease Control and Prevention (CDC). MMWR Morb Mortal Wkly Rep 2006:55:1148-51.

3. Lader D. Smoking related behaviour and attitudes, 2006. Omnibus survey report N32 UK: Office for National Statistics, 2007:77-88.

4. The Demographic Handbook of Armenia, 2005. National Statistical Service of Armenia. 2005. Yerevan, Armenia: 2005. http://www.armstat.am/en/? nid $=82$ rid $=93$ (accessed Jan 2009).

5. Hakobyan T, Nazaretyan M, Makarova T, et al. Armenia: Health system review. Health Systems in Transition 2006:8:1-180.

6. Balabanova D, McKee M, Pomerleau J, et al. Health services utilization in the former Soviet Union: Evidence from eight countries. Health Serv Res 2004;39:1927-50.

7. Official Bulletin of the Republic of Armenia 2005;8:172-6 (in Armenian).

8. National Statistical Service [Armenia], Ministry of Health [Armenia], and ORC Macro. Armenia Demographic and Health Survey 2005. Calverton, MD: National Statistical Service, Ministry of Health, and ORC Macro, 2006.

9. Poland BD, Cohen JE, Ashley MJ, et al. Heterogeneity among smokers and non-smokers in attitudes and behavior regarding smoking and smoking restrictions. Tob Control 2000;9:364-71.

10. Willemsen MC, de Vries H, Genders R. Annoyance from environmental tobacco smoke and support for no-smoking policies at eight large Dutch workplaces. Tob Control 1996;5:132-8.

11. Goodin M, McAllister I. Evaluating compliance with Australia's first smoke-free public places legislation. Tob Control 1997;6:326-31.

12. Movsisyan N, Sahakyan K, Petrosyan V, et al. Knowledge, attitudes, and practices on tobacco control policies in adult population in Armenia. Yerevan, Armenia: American University of Armenia, Center for Health Services Research and Development, 2006. http://www.auachsr.com/publications_reports2006.php (accessed Jan 2009).

13. Movsisyan N, Thompson ME, Petrosyan V. Attitudes, practices, and beliefs toward worksite smoking policy among private and public administrators in Armenia. Center for Health Services Research and Development. Yerevan, Armenia: American University of Armenia, 2005 http://www.auachsr.com/publications_reports2005.php (accessed Oct 2009).

14. Fichtenberg CM, Glantz SA. Effect of smoke-free workplaces on smoking behavior: systematic review. BMJ 2002;325:188.

15. ITC Project (February 2009). ITC France national report. University of Waterloo, Waterloo, Ontario, Canada. Paris, France: Institut national de prévention et d'éducation pour la santé (INPES), Institut national du cancer (INCa), and Observatoire français des drogues et des toxicomanies (OFDT), http://www.inpes. sante.fr/itc/pdf/ITC_rapport_EN.pdf (accessed Oct 2009). 